\title{
Surface partitioning in organic-inorganic mixtures contributes to the size-dependence of the phase-state of atmospheric nanoparticles
}

Josephina Werner, ${ }^{\text {a,b }}$ Maryam Dalirian, ${ }^{\mathrm{c}}$ Marie-Madeleine Walz, ${ }^{\mathrm{a},}{ }^{\dagger}$ Victor Ekholm, ${ }^{\mathrm{a}}$ Ulla Wideqvist, ${ }^{\mathrm{c}}$ Samuel J. Lowe, ${ }^{\mathrm{c}}$ Gunnar Öhrwall, ${ }^{\mathrm{d}}$ Ingmar Persson, ${ }^{\mathrm{b}}$ Ilona Riipinen, ${ }^{\mathrm{c},{ }^{*}}$ and Olle Björneholm ${ }^{\mathrm{a},{ }^{*}}$

${ }^{a}$ Department of Physics and Astronomy, Uppsala University, Box 516, SE-751 20 Uppsala, Sweden.

${ }^{b}$ Department of Chemistry and Biotechnology, Swedish University of Agricultural Sciences, Box 7015, SE-750 07 Uppsala, Sweden.

${ }^{\mathrm{c}}$ Department of Environmental Science and Analytical Chemistry (ACES) and Bolin Centre for Climate Research, Stockholm University, SE-106 91 Stockholm, Sweden.

${ }^{\mathrm{d}}$ MAX IV Laboratory, Lund University, Box 118, SE-221 00 Lund, Sweden.

* Corresponding authors

ABSTRACT: Atmospheric particulate matter is one of the main factors governing the Earth's radiative budget, but its exact effects on the global climate are still uncertain. Knowledge on the molecular-scale surface phenomena as well as interactions between atmospheric organic and inorganic compounds is necessary for understanding the role of airborne nanoparticles in the Earth system. In this work, surface composition of aqueous model systems containing succinic acid and sodium chloride or ammonium sulfate is determined using a novel approach combining X-ray photoelectron spectroscopy, surface tension measurements and thermodynamic modeling. It is shown that succinic acid molecules are accumulated in the surface, yielding a tenfold surface concentration as compared with the bulk for saturated succinic acid solutions. Inorganic salts further enhance this enrichment due to competition for hydration in the bulk. The surface compositions for various mixtures are parameterized to yield generalizable results and used to explain changes in surface tension. The enhanced surface partitioning implies an increased maximum solubility of organic compounds in atmospheric nanoparticles. The results can explain observations of size-dependent phase-state of atmospheric nanoparticles, suggesting that these particles can display drastically different behavior than predicted by bulk properties only.

\section{INTRODUCTION}

At the air-water interface the three-dimensional hydrogen-bonding network of water is terminated, resulting in important macroscopic phenomena such as surface tension. Microscopically this is caused by the reduced molecular coordination at the surface, which also affects the distribution of solutes in the surface region. Depending on their nature, solutes may be enriched or depleted in the surface region, but the magnitude of such effects, their molecular-scale origin and possible resulting structural changes are not well known - even for solutions with a single solute. ${ }^{1}$ Solutions with more than one solute, as often found in nature, are experimentally and theoretically even more challenging, and consequently even less well understood. 
The importance of surface phenomena increases with decreasing system size. Thus, surface phenomena can be particularly important for airborne nano-sized aerosol particles (less than a few hundred nm in diameter). Aerosol particles are ubiquitously present in the Earth's atmosphere, and their sizes range from nanometers to hundreds of micrometers. Atmospheric aerosol particles influence the climate through scattering and absorption of solar radiation as well as acting as cloud condensation nuclei (CCN). The detailed physical understanding of the behavior and impacts of aerosol particles is still incomplete, and aerosol-cloud interactions represent the largest single uncertainty in climate model predictions. ${ }^{2}$ While the importance of surface phenomena for understanding the behavior and impact of atmospheric aerosol particles has been acknowledged, ${ }^{1,3}$ bulk thermodynamics is still the standard approach for describing the chemical and physical properties, such as phase-state, volatility and chemical reactivity of these particles in atmospheric models. If the air-particle interface displays very different properties and behavior as compared with the corresponding bulk mixtures, this approach might not be appropriate. However, very few quantitative studies on the topic currently exist. $^{4-7}$

Atmospheric aerosol particles typically contain complex mixtures of inorganic and organic molecules as well as varying amounts of water, depending on the ambient conditions. Organic species constitute a particular challenge due to their complexity: while organic material can comprise up to $90 \%$ of aerosol mass, ${ }^{8}$ the organic fraction can contain thousands of different species. Significant progress has been made in the recent decades in understanding the thermodynamics of atmospheric inorganic ${ }^{9-11}$ and organic aerosol constituents, ${ }^{12-14}$ but little is known about their direct interactions with each other. ${ }^{15-18}$ These interactions are often neglected in current atmospheric models, although recent studies suggest their potential importance for nanoparticle volatility, ${ }^{19-21} \mathrm{CCN}$ activity, ${ }^{22,23}$ and ambient water content. ${ }^{24}$ Pioneering studies suggest that common inorganic salts can modify the surface propensity of typical organic molecules in atmospherically relevant mixture compositions, ${ }^{25}$ affecting the surface tension of these mixtures. ${ }^{26}$ Quantification of the magnitude of this effect in terms of surface vs. bulk concentration on the molecular scale would allow a more detailed assessment of atmospheric implications of these results.

In this study, a novel approach to quantify surface concentrations of surface-active species in the presence of highly soluble inorganic salts is introduced. The approach combines synchrotron-based X-ray photoelectron spectroscopy (XPS) experiments with measurements of macroscopic surface tension, and the interpretation of the data with thermodynamic modeling of the surface vs. bulk. While the XPS results disclose the real interfacial distribution of any species with chemical sensitivity, the conversion to absolute concentrations of the species is challenging due to the uncertainty in the attenuation length of the photoelectrons and the lack of accurate knowledge of the photoionization cross-sections. ${ }^{1}$ This uncertainty is overcome here by using surface tension data and a Langmuir adsorption model to constrain the interpretation of the XPS data. Using this approach, the surface abundance of succinic acid $\left(\mathrm{SuccH}_{2}\right)$ in aqueous solutions with and without the presence of inorganic salts, in particular ammonium sulfate $\left(\left(\mathrm{NH}_{4}\right)_{2} \mathrm{SO}_{4}\right)$ and sodium chloride $(\mathrm{NaCl})$, is quantified and parameterized. These inorganic compounds are two of the most abundant salts in atmospheric aerosol particles, originating from e.g. industrial emissions and sea spray, respectively. Succinic acid, on the other hand, is a photo-chemically produced dicarboxylic acid of mostly natural origin, and commonly found in atmospheric 
aerosol particles. The chosen mixed solutions thus serve as a surrogate for typical organic and inorganic compounds in atmospheric aerosol particles. Using these surface concentration data, the level of hydration in the surface vs. the bulk is analyzed, and implication of the results for the phase-state, properties and impacts of atmospheric nanoparticles containing mixtures of organic and inorganic substances are discussed.

\section{MATERIALS AND METHODS}

\section{The studied systems}

Succinic acid in aqueous electrolyte solutions of $\mathrm{NaCl}$ or $\left(\mathrm{NH}_{4}\right)_{2} \mathrm{SO}_{4}$ was experimentally investigated through probing the molecular-scale surface compositions of a liquid micro-jet with XPS and measuring surface tension. A list of all sample solutions and corresponding additional information, such as $\mathrm{pH}$ values and densities, are given in the Supporting Information (SI), Table S1.

All bulk concentrations are given in mole fractions $x=\frac{n_{\text {solute }}}{n_{W}+n_{\text {solute }}}$, where $n_{\text {solute }}$ is the number of moles of the solute and $n_{W}$ the number of moles water. Mixed aqueous solutions are described by two mole fractions: one for the organic acid $x_{\text {org }}$ and one for the inorganic salt $x_{\text {inorg }}$, given for each solute separately with respect to the water content. The surface mole fractions $s$ are calculated correspondingly. Molar concentrations $c$ in $\left[\mathrm{mol} / \mathrm{dm}^{3}\right]$ are used when the direct relation to the surface photoemission (PE) intensities (denoted by $I^{s}$ ) is discussed. Conversions between these quantities are provided in the SI.

\section{XPS experiments}

The XPS experiments were performed at the Swedish National Synchrotron Facility MAX-lab, Lund University, at the soft X-ray beamlines I411 and I1011 (Max-II ring). The experimental setup and conditions are the same as described elsewhere. ${ }^{1,27}$

Sample solutions were prepared freshly from commercially available chemicals (Sigma Aldrich with the purities: $>99.5 \%$ for SuccH $\mathrm{H}_{2}$ and $\mathrm{NaCl}$ and $>99 \%$ for $\left.\left(\mathrm{NH}_{4}\right)_{2} \mathrm{SO}_{4}\right)$ and demineralized water $(18.2 \mathrm{M} \Omega \cdot \mathrm{cm}$, Milli-pore Direct-Q) for all experiments. For the XPS experiments, stock solutions of the organic acid were prepared for each series of experiments and inorganic salts were added. Prior to experiment the sample solutions were filtered (Whatman Puradisc FP30 syringe filters, $1.2 \mu \mathrm{m}$ pore size) to remove potential dust. Sample solutions for surface tension measurements were prepared freshly using the required amount of organic and inorganic compound.

To assess the effects of $\mathrm{NaCl}$ and $\left(\mathrm{NH}_{4}\right)_{2} \mathrm{SO}_{4}$ on the abundance of $\mathrm{SuccH}_{2}$ at the aqueous surface, the carbon $1 \mathrm{~s}(\mathrm{C} 1 \mathrm{~s})$ core level PE signal of the acid was compared between the mixed solution with added inorganic salts and the pure SuccH $\mathrm{H}_{2}$ solution. Changes in the surface abundance of the inorganic salts were monitored via the nitrogen $1 \mathrm{~s}(\mathrm{~N} 1 \mathrm{~s})$ of ammonium ions, sulfur $2 \mathrm{p}(\mathrm{S} 2 \mathrm{p})$ of sulfate ions and chlorine $2 \mathrm{p}(\mathrm{Cl} 2 \mathrm{p})$ of chloride ions. The $\mathrm{C} 1 \mathrm{~s} \mathrm{PE}$ lines were measured at a photon energy of $360 \mathrm{eV}, \mathrm{Cl} 2 \mathrm{p}$ at 270 $\mathrm{eV}, \mathrm{N} 1 \mathrm{~s}$ at $480 \mathrm{eV}$ and $\mathrm{S} 2 \mathrm{p}$ at $240 \mathrm{eV}$, resulting in roughly $70 \mathrm{eV}$ kinetic energy for each of the core levels and the same short probing depth for all species. ${ }^{28,29}$ For each investigated core level region also the $1 b_{1}$ valence PE spectrum of liquid water was recorded and used to calibrate the kinetic energy scale, by aligning the $1 \mathrm{~b}_{1}$ PE line of liquid water to $11.16 \mathrm{eV}^{30}$ with an uncertainty in binding energy of $50 \mathrm{meV}$. All PE spectra were intensity normalized accounting for variations in photon flux from the synchrotron 
ring and the acquisition time. To monitor the stability of the experimental setup, the $1 \mathrm{~b}_{1} \mathrm{PE}$ line of liquid water of a $50 \mathrm{mM} \mathrm{NaCl}$ solution was measured between each sample solution. Only experiments with these reference intensities within $5 \%$ were further used in the analysis. PE peak areas were extracted from the recorded spectra by curve fitting. Details on the spectral analysis can be found in the SI.

\section{Interpretation of XPS experiments with Langmuir adsorption model and binary surface tension data}

A model based on the Langmuir adsorption theory was used together with surface tension measurements for pure Succ $\mathrm{H}_{2}$ aqueous solutions ${ }^{1}$ to quantify the surface concentrations from the XPS results. The Langmuir model has been previously applied to XPS results, ${ }^{31,32}$ and enables the estimation of surface concentrations as well as the net energy gain for a solution with a portion of a single solute accumulated at the interface, i.e. free energy of adsorption $\Delta G_{a d s}$. The surface is assumed to be represented by a monolayer with no interactions between adsorbed molecules. ${ }^{33}$ Even though these are simplifications of the reality, the Langmuir model provides a useful framework for the interpretation of the results, as shown in this work.

The surface component $I^{s}$ of the total recorded PE signal $I^{\text {tot}}$, which contains contributions from the surface region and the surface-near-bulk region, can be described as a function of bulk mole fraction $x$ of a compound in aqueous solution using the Langmuir adsorption isotherm:

$I^{S}=\frac{I^{s, \max } \cdot x}{x+(1-x) \cdot e^{\frac{\Delta G a d s}{R T}}}$,

where $I^{s, \max }$ is the maximum surface contribution of the PE signal. $R$ is the universal gas constant and $T$ the absolute temperature, which was $283.15 \mathrm{~K}$ corresponding to the temperature of the XPS experiments.

To determine $I^{s, m a x}$ and $\Delta G_{a d s}$ for the pure succinic acid solutions, Eq. 1 was fitted to previously published XPS results. ${ }^{1} I^{s}$ was estimated assuming the PE signal of the succinate ion $\left(\mathrm{Succ}^{2-}\right)$ to originate solely from the bulk of the solution, while the $\mathrm{SuccH}{ }_{2}$ signal corresponds to both the surface and the bulk. ${ }^{1}$ Hence, the surface contribution $I^{s}$ is given by the difference $I^{s}=I^{\text {tot }}-$ $I_{\text {Succ }^{2-}}$. As the PE signal is directly proportional to the number of a species in the probed volume, $I^{s}$ is directly proportional to the surface concentration $c^{s}$ in $\left[\mathrm{mol} / \mathrm{dm}^{3}\right]$ of $\mathrm{SuccH}_{2}$ at any given $x . I^{s, \max }$, on the other hand, corresponds to the surface PE signal of a saturated surface region. If the molar concentration $c^{\text {s,max }}$ and the surface mole fraction $s^{\max }$ corresponding to $I^{s, \max }$, are known, the molar surface concentration $c^{s}$ at any given $x$ can be estimated using Eq. 1 with the fitted $I^{s, m a x}$ and $\Delta G_{a d s}$ values and $I^{s} / I^{s, \max }=c^{s} /$

$c^{s, \max } \cdot{ }^{32}$ Here, $c^{s, \max }$ was estimated by choosing a value that successfully reproduced surface tension data of pure $\mathrm{SuccH}_{2}$ solutions.

To quantify the effect of the inorganic salts on the surface propensity of $\mathrm{SuccH}_{2}$, it is assumed that $I^{s, \text { max }}$ determined from pure $\mathrm{SuccH}_{2}$ solutions is not exceeded in the mixed electrolyte solutions, allowing the effect of the inorganic salts to be expressed as a change in $\Delta G_{a d s}$ via Eq. 1. This is equivalent to assuming that $\mathrm{SuccH}_{2}$ molecules dominate the solute population in the interfacial region, while the inorganic ions primarily reside in the bulk of the solution - an assumption that was further investigated using XPS. $c^{s}$ of $\mathrm{SuccH}_{2}$ in mixed solutions are obtained in the same way as described for the pure solutions above. Finally, this approach, 
including the quantified surface concentrations of $\mathrm{SuccH}_{2}$ in electrolyte solutions of varying concentration, was evaluated through comparisons to surface tension data of corresponding solutions.

\section{Surface tension measurements}

Surface tension measurements were performed for pure and mixed aqueous solutions of $\mathrm{SuccH}_{2}$ and $\left(\mathrm{NH}_{4}\right)_{2} \mathrm{SO}_{4}$ in a temperaturecontrolled room at $283.15 \mathrm{~K}$. The surface tension as a function of concentration was determined by a FT 125 tensiometer (First Ten Ångstroms) using the pendant drop shape method, which was calibrated using demineralized water $(18.2 \mathrm{M} \Omega \cdot \mathrm{cm}$, Milli-pore Direct-Q). Measurements for each sample were repeated until the surface tension value of three consecutive droplets resulted in an average absolute deviation of less than $0.5 \%$. Surface tension was calculated using the program FTA 32 , with approximately 43 photos of each droplet and densities of the sample solutions, which were determined at 298.15 K using an Anton Paar DMA densiometer and scaled using the density of pure water at $298.15 \mathrm{~K}$ and $283.15 \mathrm{~K}$.

\section{Model connecting surface tension to surface and bulk composition}

The surface tension model by Sprow and Prausnitz $\mathrm{z}^{34,35}$ was used to estimate the surface tension of pure and mixed solutions. This model was used by Li et al. ${ }^{36}$ for aqueous electrolyte solutions and later by Werner et al. ${ }^{1}$ for pure aqueous succinic acid solutions, where a detailed description of the procedure is given. Assuming a thermodynamic equilibrium between the surface and the bulk region, the surface tension of the aqueous solution $\sigma_{\text {sol }}$ can be approximated as

$\sigma_{\text {sol }}=\sigma_{w}+\frac{R T}{A_{w}} \ln \frac{a_{w}^{S}}{a_{w}^{b}}$

where $\sigma_{\mathrm{w}}$ is the surface tension of pure water and $A_{\mathrm{w}}$ is the molar surface area of water. $a_{w}^{s}$ and $a_{w}^{b}$ are the activities of water in the surface and bulk, respectively, which are directly proportional to the mole fraction and activity coefficients of water in these phases. To calculate the activity coefficients of water for the mixed organic-inorganic solutions in the bulk and surface region, two thermodynamic models were used: The Extended UNIFAC model (E-UNIFAC) ${ }^{37}$ and the Extended AIM Aerosol Thermodynamics Model (E-AIM). ${ }^{15,16}$ Both of them use the original UNIFAC model, which is a group contribution model for short-range contributions. ${ }^{12}$ For the E-UNIFAC model the group contribution parameters were extracted from Raatikainen and Laaksonen, ${ }^{37}$ and for the E-AIM model, the parameterization of Peng et al. ${ }^{38}$ was used.

\section{RESULTS AND DISCUSSION}

\section{Surface composition of the pure succinic acid solutions}

The PE intensities for pure aqueous $\mathrm{SuccH}_{2}$ as a function of the bulk composition, which were part of a previous study, ${ }^{1}$ are shown in Fig. 1a together with the Langmuir fit (see Eq. 1). The Gibbs free energy of adsorption of aqueous $\mathrm{SuccH}_{2}$ to the surface was determined to be $\Delta G_{a d s}=-12.8 \mathrm{~kJ} / \mathrm{mol}$. In comparison with butanol $\left(-15.3 \mathrm{~kJ} / \mathrm{mol}^{32}\right)$, which is a less strongly hydrated compound, or thiocyanate $\left(-6 \mathrm{~kJ} / \mathrm{mol}^{39}\right)$ that is more strongly hydrated due to its charge and size and therefore less abundant in the aqueous surface region, the obtained value for $\mathrm{SuccH}_{2}$ seems reasonable. The resulting surface concentrations (see Fig. 1a, right 
axis, where the surface concentration $c^{s, \max }$ corresponding to the fitted maximum PE signal $I^{s, \max }$ was set to $8 \mathrm{~mol} / \mathrm{dm}^{3}, \mathrm{yielding} s^{\max }$ $=0.26806$ ) agree well with estimates from a previous study and experimentally obtained surface tension data, see Fig. $1 \mathrm{~b}$.

Generally, the surface concentration of succinic acid is strongly increased in pure solutions. The tight packing of Succ $\mathrm{H}_{2}$ in the interfacial region implies a higher solubility in the surface region than in the bulk of the solution. Defining the surface solubility limit $c^{\text {s,limit }}$ to be the surface concentration corresponding to a saturated bulk solution above which bulk precipitation sets in $\left(x^{\text {lim- }}\right.$ $\left.{ }^{i t}=0.01015^{41}\right), c^{\text {s,limit }}$ is determined to be $5.6 \mathrm{~mol} / \mathrm{dm}^{3}$ at $283.15 \mathrm{~K}\left(s^{\text {limit }}=0.14867\right)$, which corresponds to roughly $70 \%$ of $c^{s, m a x}$.

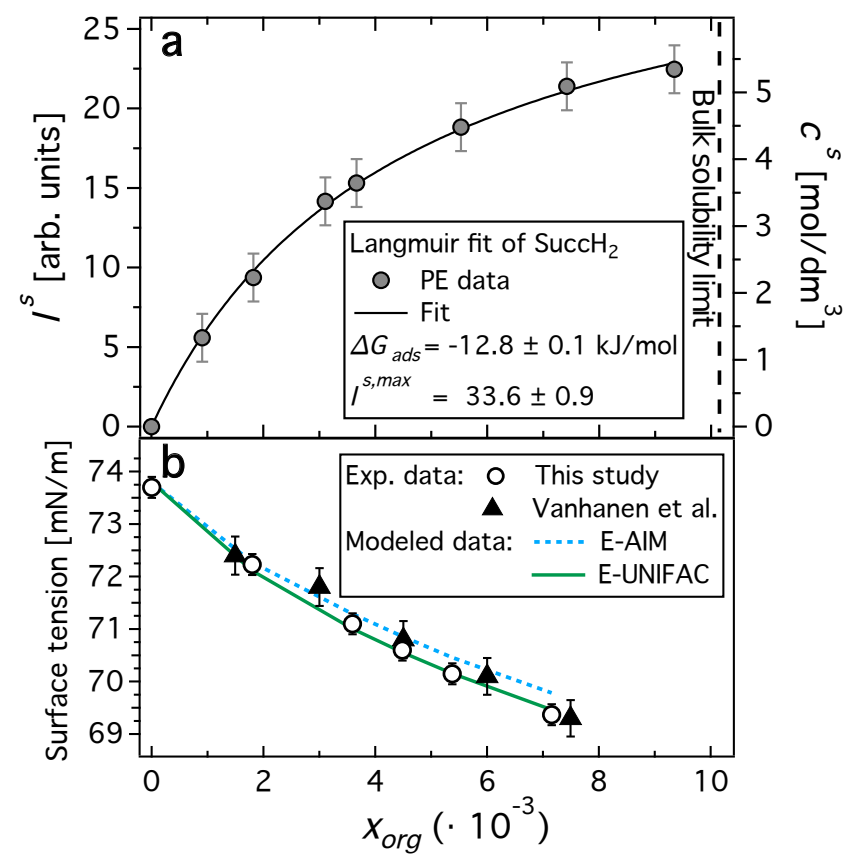

Figure 1. The surface propensity and surface tension of pure succinic acid in aqueous solutions. a. Experimental and fitted surface PE intensities as a function of bulk mole fractions of aqueous $\mathrm{SuccH}_{2}\left(x_{\text {org }}\right)$. The right axis shows corresponding molar surface concentrations. b. Experimental (Ref. 40 and this work) and modeled surface tension as a function of $x_{\text {org }}$ aqueous Succ $\mathrm{H}_{2}$. Note that for a single organic compound in aqueous solution, the principles utilized in E-AIM and E-UNIFAC are identical. Differences between these models are caused by different group contribution parameters. Error bars are estimated from experimental uncertainties.

\section{Surface composition of mixed solutions}

The ratios of the PE intensities of $\mathrm{SuccH}_{2}$ in aqueous solutions as a function of $\mathrm{NaCl}$ or $\left(\mathrm{NH}_{4}\right)_{2} \mathrm{SO}_{4}$ are assembled for the studied solutions in Fig. 2a as a function of the mole fraction of the added inorganic salt $x_{\text {inorg. }}$ The $\mathrm{C} 1 \mathrm{~s}$ signal of $\mathrm{SuccH}_{2}$ increases roughly linearly with inorganic salt concentration (see also SI, Fig. S1). The Cl 2p, S 2p and N 1s PE intensities of the inorganic ions in mixed solution with $\mathrm{SuccH}_{2}$ (at $x_{\text {org }}=0.00489$ ) and pure electrolyte solutions (at $x_{\text {inorg }}=0.01770$ for $\left(\mathrm{NH}_{4}\right)_{2} \mathrm{SO}_{4}$ and $x_{\text {inorg }}=0.05127$ for $\mathrm{NaCl}$ ) are also compared (Fig. 2a). The results suggest that the spatial distribution of the ions is not affected by the addition of $\mathrm{SuccH}_{2}$ to the electrolyte solution within experimental uncertainties. This supports the assumption of strongly hydrated ions being depleted from the aqueous surface, as also suggested from Gibbs theory for compounds that increase the surface tension of a solu- 
tion. $^{42}$ It can be concluded that in these electrolyte solutions, succinic acid resides closer to the interface, while the inorganic ions remain unaffected by the co-dissolved organic acid in the bulk of the solution.

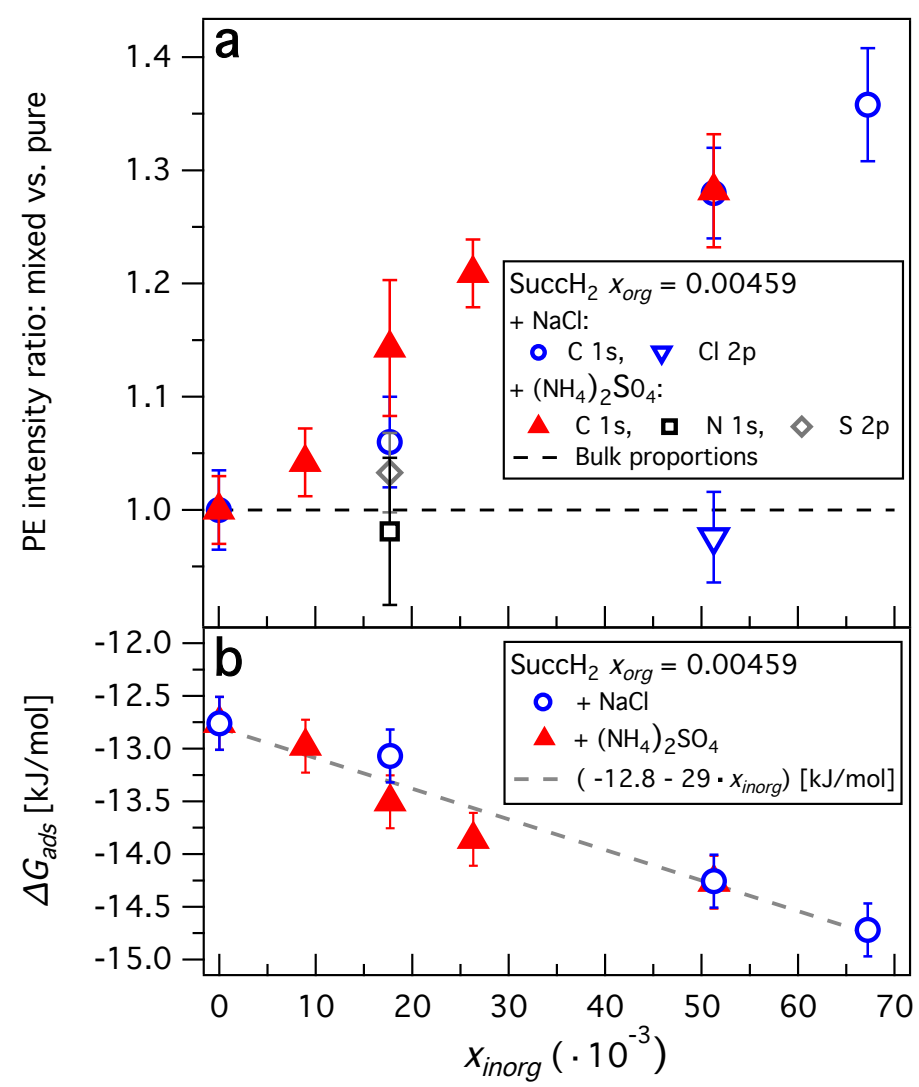

Figure 2. The effect of inorganic salts on the surface propensity of succinic acid. a. PE intensity ratios of $\mathrm{C} 1 \mathrm{~s}, \mathrm{Cl} 2 \mathrm{p}, \mathrm{N} 1 \mathrm{~s}$ and $\mathrm{S} 2 \mathrm{p}$ of aqueous electrolyte solutions of $\mathrm{SuccH}_{2}\left(x_{\text {org }}=0.00459\right)$ and various amounts of added $\mathrm{NaCl}$ or $\left(\mathrm{NH}_{4}\right)_{2} \mathrm{SO}_{4}$. Intensities of the mixed solutions are always related to the PE intensities of pure solutions. The dashed line indicates the bulk proportions. b. $\Delta G_{a d s}$ under the assumption that the surface is only populated by $\mathrm{SuccH}_{2}$ and the bulk contains both inorganic ions and $\mathrm{SuccH}_{2}$. The trend is approximated using Eq. 3. Error bars are estimated from experimental uncertainties.

The $\Delta G_{a d s}$ values for the mixed solutions and the fitted value for the maximum PE intensity $I^{\text {s, } \max }=33.6$, are shown in Fig. $2 \mathrm{~b}$ as a function of $x_{\text {inorg. }}$ The decreasing $\Delta G_{a d s}$ values can be parameterized using Eq. 3, and represent the net energy gain for the mixed solution by a portion of the dissolved $\mathrm{SuccH}_{2}$ being accumulated at the interface.

$\Delta G_{a d s}=\left(-12.8-29 \cdot x_{\text {inorg }}\right)[\mathrm{kJ} / \mathrm{mol}]$

The $\Delta G_{a d s}$ values become more and more negative for increasing amounts of added inorganic salt, indicating that the accumulation of $\mathrm{SuccH}_{2}$ at the surface is increasingly favorable for the aqueous system when strongly hydrated ions are present in solution.

Using the proposed parameterizations (Eq. 1 and 3), the surface composition of the mixed solutions can be described for any combination of $\mathrm{SuccH}_{2}$ and $\mathrm{NaCl}$ or $\left(\mathrm{NH}_{4}\right)_{2} \mathrm{SO}_{4}$. The resulting $I^{s}$ as a function of organic and inorganic mole fractions are shown in 
Fig. $3 \mathrm{a}$, and the corresponding surface tension predictions are shown in Fig. $3 \mathrm{~b}$ for mixed solutions containing $\mathrm{SuccH}_{2}$ and $\left(\mathrm{NH}_{4}\right)_{2} \mathrm{SO}_{4}$. Experimentally obtained surface tension data for mixed solutions containing $\mathrm{SuccH}_{2}$ and $\mathrm{NaCl}^{40}$ or $\left(\mathrm{NH}_{4}\right)_{2} \mathrm{SO}_{4}(\mathrm{compare}$ Table S2) are also shown in Fig. 3b. The modeled surface tension values fit very well with the experimentally obtained ones throughout the concentration range, supporting the applied approach and its underlying assumptions. Generally, surface tension increases for solutions containing one of the inorganic salts and decreases if only succinic acid is present as solute.
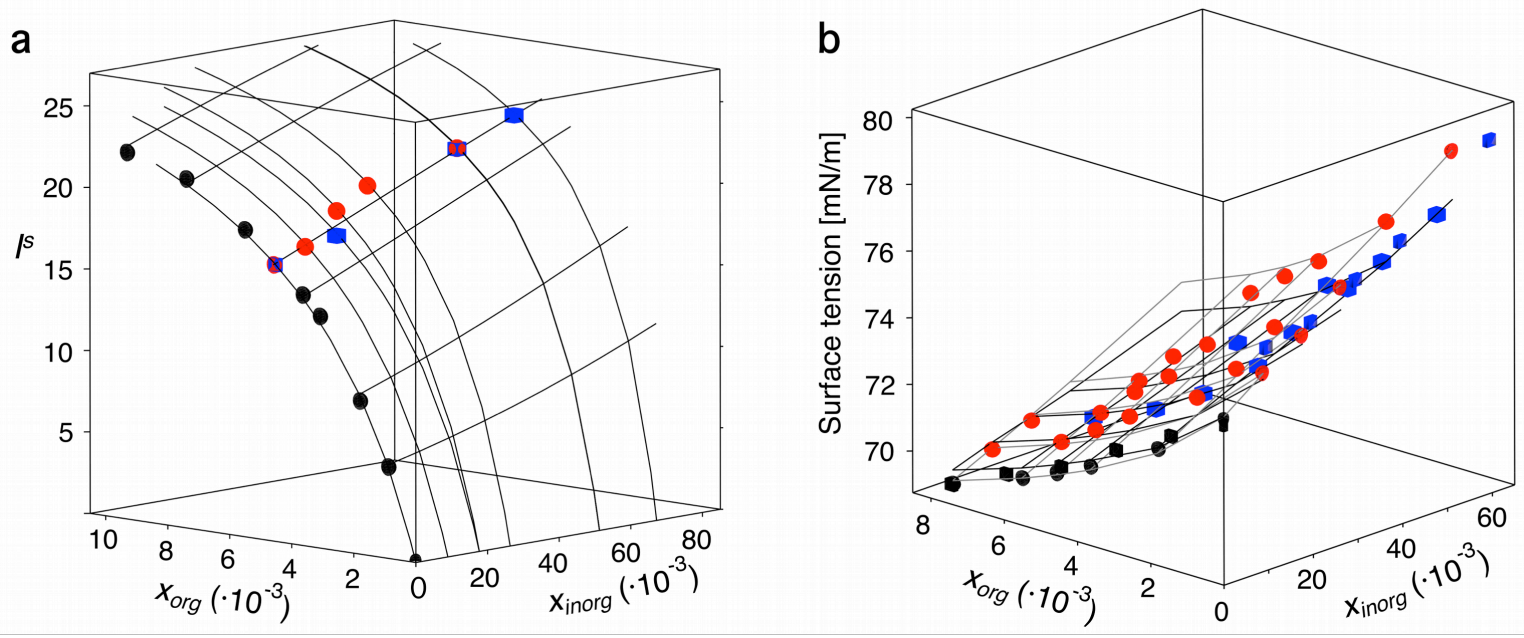

Figure 3. Experimentally determined and parameterized PE signals and surface tensions as a function of mixed solution composition. a.

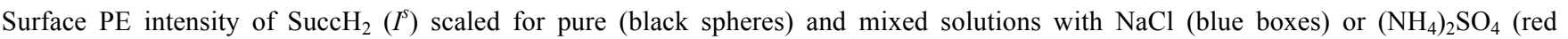
spheres). The black lines are parameterized $I^{s}$ values (see Eq. 1). b. Surface tension as a function of solution composition. Experimental values from $\mathrm{SuccH}_{2}$ with $\left(\mathrm{NH}_{4}\right)_{2} \mathrm{SO}_{4}$ (listed in Table S2) and $\mathrm{NaCl}$ (taken from Ref. 40) are shown. Modeled surface tension of mixed solutions containing from $\mathrm{SuccH}_{2}$ with $\left(\mathrm{NH}_{4}\right)_{2} \mathrm{SO}_{4}$ are shown as lines, where activities calculated via the E-AIM model and E-UNIFAC model are shown in black and grey, respectively.

\section{Hydration in the bulk and at the surface}

The number of water molecules required for the first hydration shell of $\mathrm{Na}^{+}$and $\mathrm{Cl}^{-}$is 6 each, ${ }^{43,44}$ for $\mathrm{NH}_{4}^{+}$it is $4^{45}$ and for $\mathrm{SO}_{4}{ }^{2-}$ it is $12^{46}$. Water interacts strongly with the polar carboxylic acid groups of a dicarboxylic acid, while the interactions with the hydrophobic $-\mathrm{CH}_{2-}$ (methylene) groups are unfavorable and water molecules form a "void" around them to minimize the unfavorable interactions. The number of water molecules that surround one carboxylic acid group is on average $2.5 .^{47}$ Hence, 5 water molecules are used per $\mathrm{SuccH}_{2}$ molecule as a limit for full hydration in the further analysis.

To estimate the degree of hydration, the number of water molecules employed in the first hydration shell of the solute species was calculated for each bulk solution composition and compared to the total number of available water molecules. The resulting percentage of strongly bound water $\left(\mathrm{W}_{\%}\right)$, the number of water molecules available for each $\mathrm{SuccH}_{2}$ molecule in the bulk and at the 
surface $\left(\mathrm{N}_{\mathrm{W} / \text { org }}\right)$, as well as the relative enhancement of $\mathrm{SuccH}_{2}$ in the surface compared to the bulk $\left(s_{\text {org }} / x_{\text {org }}\right)$ are listed in Table 1 for each studied solution. Details on the derivation of these values can be found in the SI.

Table 1. The bulk vs. surface hydration of the succinic acid molecules in the studied solutions.

\begin{tabular}{|c|c|c|c|c|c|c|}
\hline & $\mathbf{x}_{\text {org }}$ & $\mathbf{x}_{\text {inorg }}$ & $\begin{array}{l}\mathbf{W}_{\%} \\
{[\%]}\end{array}$ & $\begin{array}{l}\text { Bulk } \\
\text { N }_{\text {W/Org }}\end{array}$ & $\begin{array}{l}\text { Surface } \\
\mathbf{N}_{\text {W/Org }}\end{array}$ & $s_{\text {org }} / x_{\text {org }}$ \\
\hline pure & 0.00459 & - & 2.2 & 222.0 & 9.6 & 20.7 \\
\hline $\begin{array}{c}\text { saturated } \\
. .\end{array}$ & 0.01015 & - & 5.1 & 97.5 & 5.7 & 14.6 \\
\hline \multirow[t]{3}{*}{$+\mathrm{NaCl}$} & 0.00459 & 0.01770 & 23.9 & 174.0 & 8.7 & 22.4 \\
\hline & 0.00459 & 0.05127 & 67.1 & 78.0 & 6.3 & 29.7 \\
\hline & 0.00459 & 0.06722 & 87.7 & 30.0 & 5.7 & 32.5 \\
\hline \multirow{4}{*}{$\begin{array}{l}+ \\
\left(\mathrm{NH}_{4}\right)_{2} \mathrm{SO}_{4}\end{array}$} & 0.00459 & 0.00893 & 20.3 & 182.0 & 9.0 & 21.9 \\
\hline & 0.00459 & 0.01770 & 38.3 & 142.0 & 7.7 & 25.0 \\
\hline & 0.00459 & 0.02631 & 56.3 & 102.0 & 7.0 & 27.2 \\
\hline & 0.00459 & 0.05127 & 110.3 & -18.0 & 6.3 & 29.8 \\
\hline
\end{tabular}

The electrolyte solutions investigated in this work are highly concentrated, and in many cases more than $50 \%$ of the available water is strongly involved in the direct hydration of the dissolved species. As the amount of available water molecules decreases, the species in solution start to compete for full hydration. It becomes energetically beneficial to hydrate the ionic species (inorganic salts) in the bulk of the solution, allowing the more weakly hydrated species $\left(\mathrm{SuccH}_{2}\right)$ to populate the less favorable surface sites. As each $\mathrm{SuccH}_{2}$ molecule only requires 5 water molecules for hydrogen bonding and additionally possesses a hydrophobic alkylchain, it is segregated to the aqueous surface, where its central part $\left(-\mathrm{CH}_{2}-\mathrm{CH}_{2}-\right)$ can be partially dehydrated. ${ }^{1,48}$ As more than the available water is required in case of $x_{\text {org }}=0.00459$ with $x_{\text {inorg }}=0.05127$ of $\left(\mathrm{NH}_{4}\right)_{2} \mathrm{SO}_{4}$, the water molecules are likely shared between the species promoting also direct interactions between the dissolved species, ${ }^{49}$ which may affect the volatility of the compounds. $^{21}$

The quantitative estimate of the $\mathrm{SuccH}_{2}$ concentration at the surface allows for separate investigation of the hydration at the surface, comparing bulk and surface $N_{W / O r g}$ in Table 1 . In case of the pure $\mathrm{SuccH}_{2}$ solution $\left(x_{\text {org }}=0.00459\right)$, the carboxylic acid groups at the surface are sufficiently hydrated and there are roughly 5 water molecules per $\mathrm{SuccH}_{2}$ left to hydrate the central part of the molecule, which is thus at least partially hydrated. In the more concentrated electrolyte solutions, more succinic acid molecules are accumulated in the interfacial region, reducing the number of $\mathrm{H}_{2} \mathrm{O}$ per acid to roughly 6 , which is close to the value found for a saturated pure succinic acid solution with $x^{\text {limit }}$ and $s^{\text {limit }}$. The $\mathrm{SuccH}_{2}$ molecules at the interface are packed efficiently, but not as 
tightly as in a dry crystal, ${ }^{50,51}$ as the few water molecules per acid are integrated into the $\mathrm{SuccH}_{2}$-dominated surface region. For a saturated pure succinic acid solution with $x^{\text {limit }}=0.01015$ and $s^{\text {limit }}=0.14867$, the corresponding number of water molecules per acid in the surface is 5.7, which is enough to hydrate the carboxylic acid groups but not the methylene groups.

The relative enhancement of $\mathrm{SuccH}_{2}$ in the surface compared to the bulk of the solution, which is given by the ratio of the corresponding mole fractions $s_{\text {org }} / x_{\text {org }}$, is listed in Table 1 for each studied solution. It can be seen that the addition of inorganic ions in the bulk of the solution causes a strong increase in the surface concentration of the organic acid.

\section{Size-dependent particle content and phase-state}

The results in this study suggest that the water-solubility of succinic acid is strongly increased in the surface region as compared with the bulk solution, and this effect is further enhanced by the presence of highly soluble inorganic salts like $\mathrm{NaCl}_{\text {and }}\left(\mathrm{NH}_{4}\right)_{2} \mathrm{SO}_{4}$ (Table 1). This has important implications for the phase of aqueous nanoparticles containing these chemical compounds.
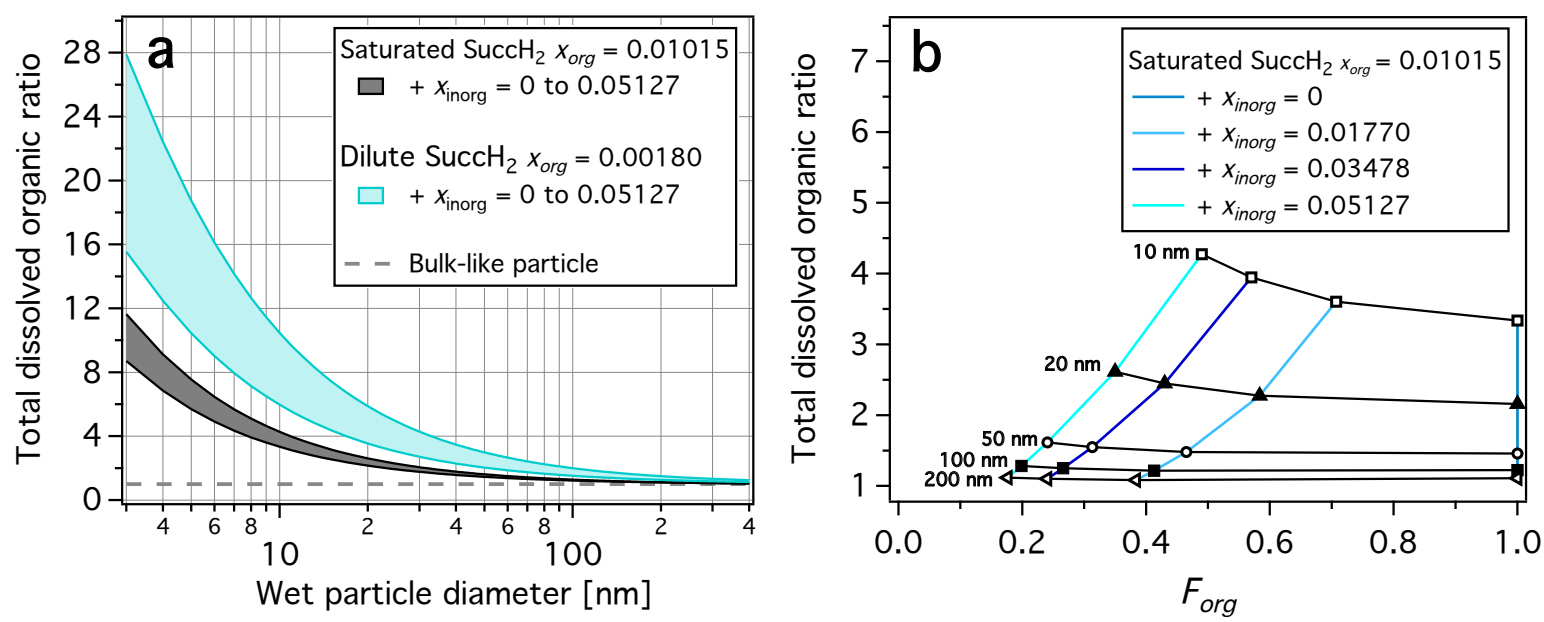

Figure 4. Organic acid loading in aqueous nanoparticles. a. The total dissolved organic ratio of a partitioned particle vs. a bulk-like particle is shown as a function of wet particle diameter for the case of saturated and dilute $\mathrm{SuccH}_{2}$ with and without $\left(\mathrm{NH}_{4}\right)_{2} \mathrm{SO}_{4}$. b. The total dissolved organic ratio as a function of organic fraction $F_{\text {org }}$ for various wet particle diameters and different amounts of added inorganic salt. Details on the estimations presented in these figures can be found in the SI.

Due to the high surface-to-volume ratio of these particles, a strong enhancement of their effective solubility as compared with bulk-like particles can be seen for wet particle diameters smaller than about $200 \mathrm{~nm}$, see Fig. 4. Such nanoparticles thus stay in the aqueous liquid phase even at total succinic acid concentrations clearly above the bulk solubility limit. The enhancement is relatively stronger for the lower $\mathrm{SuccH}_{2}$ content and more pronounced in the presence of inorganic salts (Fig. 4a and SI for details). Hence, the importance of the surface region for the total organic content is bigger for more dilute mixtures where the surface is far from saturation. Small particles can contain a multiple of the expected bulk content, depending on the organic fraction. As shown in 
Fig. 4b, for a particle with maximum $\mathrm{SuccH}_{2}$ loading in the bulk of the solution, i.e. saturated with succinic acid, and different amounts of $\left(\mathrm{NH}_{4}\right)_{2} \mathrm{SO}_{4}$ (i.e. varying $\left.F_{\text {org }}=\frac{n_{\text {org }}}{n_{\text {inorg }}+n_{\text {org }}}\right)$, the effect is strongest for small particles and $F_{\text {org }}<0.7$.

These molecular phenomena help to explain observations on the size-dependence of the phase-state of atmospherically relevant nanoparticles, where generally a well-mixed liquid phase is observed at smaller particle sizes (less than about 100-200 nm), even for the mixtures where larger particles show phase separation. ${ }^{52-54}$ The presented results thus support the general suggestions by Cheng et al., ${ }^{55}$ where the effect of the surface on the size-dependence of water-solubility and hygroscopicity was discussed, although not directly quantified on a molecular level. Furthermore, our observations are qualitatively in line with the studies on phaseseparated micro-scale droplets that show the accumulation of organic compounds at the surface, while highly soluble inorganic salts form an aqueous solution in the center of the droplet. ${ }^{24,56,57}$ The proposed mechanism may of course not be the only possible explanation for the size-dependent phase state of atmospheric droplets, but it is probably one mechanism contributing to the phenomenon.

Enhanced liquid phase of atmospheric nanoparticles as compared with the corresponding bulk predictions affects particle-phase chemical reaction rates, ${ }^{58}$ enhances the particle-phase mass transfer, ${ }^{59,60}$ increases the CCN activity ${ }^{23,61}$ as well as affects the optical properties and direct radiative impacts ${ }^{62,63}$ of these particles. In particular, the molecular-scale observations presented here may help to explain why even small amounts of inorganic salt seem to enhance the $\mathrm{CCN}$ activation of organic molecules more than expected based on bulk solubility considerations only. ${ }^{22,61}$ Surface partitioning of organic species naturally also influences the CCN activation and hygroscopic growth of atmospheric particles directly, through the effects of surface tension and bulk activity on the equilibrium vapor pressure of water over these solution droplets. ${ }^{4,26,64,65}$ However, this direct effect of the aqueous surface composition on the CCN activation is very small $(<1 \%$ in the activation dry diameter, see Fig. S3) for the mixtures studied here, suggesting that the surface vs. bulk partitioning of these systems indeed manifests itself primarily through affecting the phase-state of nanoparticles.

Even though only one atmospherically relevant organic acid has been studied here, it is likely that the results are at least partly generalizable to other atmospheric organic components as well - in particular those with similar moderate surface activity. The driving factor for the surface-enhancing capacity of the inorganic salts originates from the competition of the solute species on the hydrating water molecules. Moreover the effect is bigger for a low organic content of a moderately surface-active compound as compared with high organic content, which is attributed to the relative coverage of the surface, see also Fig. 3a. This is in line with previous observations. ${ }^{53,66}$ The detailed behavior of the different molecules at the surface may vary however, as pointed out by e.g. Refs. 25 and 32, who report differences in the surface organization of dicarboxylic acids with even vs. odd carbon numbers and positional isomers of alkyl-alcohols.

To summarize, the presented results indicate that common atmospheric inorganic salts can significantly alter the surface propensity of less soluble organic species in atmospheric droplets, thus affecting the surface tensions of liquid aerosol particles containing these compounds. Due to the high surface-to-bulk ratio of small atmospheric droplets and an enhanced concentration of the organic 
species in the surface as compared with the bulk, liquid aerosol particles can be loaded with significantly larger amounts of organic compounds than indicated by the bulk solubility limit. These results may explain the previously observed size-dependent phasestate of aerosol nanoparticles containing organic molecules. As the apparent solubility in atmospheric nanoparticles can be substantially higher than the bulk solution solubility limit, the contribution of particle surface needs to be considered when modeling the phase and water content of such particles. The importance of the surface strongly depends on the particle diameter and amount of co-dissolved inorganic salt. The presented interactions between atmospheric inorganic and organic particle constituents may moreover influence the water content and $\mathrm{CCN}$ activity of atmospheric particles. The results suggest that properties of aqueous nanoparticles can deviate fundamentally from predictions based on bulk properties only - particularly when it comes to predicting their phase-state in the presence of water. It should be noted, however, that here we have focused only on the thermodynamic of the condensed phase. While this is appropriate for particles/compounds with low volatility, in the atmosphere also the simultaneous partitioning between the gas and the condensed phases should be accounted for when considering semi-volatile species.

\section{ASSOCIATED CONTENT}

\section{Supporting Information}

Information contains a list of the compositions and $\mathrm{pH}$ values of the sample solutions investigated by XPS (Table S1), example spectra (Fig. S1) and details on the curve fitting procedure. Furthermore, a list of the densities and measured surface tension values (Table S2), as well as the conversion calculation between the different concentration units used throughout this article. Detailed information on the derivation of values listed in Table 1 and the derivation of the organic acid content in small droplets are given. Results of calculations investigating the role of our results on CCN activation (Fig. S3) are shown. The Supporting Information is available free of charge on the ACS Publications website.

\section{AUTHOR INFORMATION}

\section{Corresponding Authors}

*Email: olle.bjorneholm@physics.uu.se, phone: +46184713618 and email: ilona.riipinen@aces.su.se, phone: +46 86747284.

\section{Present Addresses}

${ }^{\dagger}$ Department of Cell and Molecular Biology, Uppsala University, Box 596, SE-751 24 Uppsala, Sweden.

\section{Notes}

The authors declare no competing financial interest.

\section{ACKNOWLEDGMENT}

Financial support from the Swedish Research Council (VR), Swedish Foundation for Strategic Research, the Carl Tryggers foundation (MMW) and European Research Council (ERC-StG-27882 ATMOGAIN) is gratefully acknowledged. MAX-lab, Lund University, Swe- 
den is acknowledged for the allocation of beamtime and laboratory facilities. Jan Julin is acknowledged for valuable contributions to the discussion of the results.

\section{REFERENCES}

(1) Werner, J.; Julin, J.; Dalirian, M.; Prisle, N. L.; Ohrwall, G.; Persson, I.; Björneholm, O.; Riipinen, I. Succinic Acid in Aqueous Solution: Connecting Microscopic Surface Composition and Macroscopic Surface Tension. Phys. Chem. Chem. Phys. 2014, 16 (39), $21486-21495$.

(2) Stocker, T.; Qin, D.; Plattner, G.; Tignor, M. Climate Change 2013: The Physical Science Basis.; Cambridge University Press, 2013.

(3) Facchini, M. C.; Mircea, M.; Fuzzi, S.; Charlson, R. J. Cloud Albedo Enhancement by Surface-Active Organic Solutes in Growing Droplets. Nature 1999, 401 (6750), 257-259.

(4) Sorjamaa, R.; Svenningsson, B.; Raatikainen, T.; Henning, S.; Bilde, M.; Laaksonen, A. The Role of Surfactants in Köhler Theory Reconsidered. Atmos. Chem. Phys. 2004, 4 (8), 2107-2117.

(5) Laaksonen, A., McGraw, R., Vehkamäki, H., Liquid-drop formalism and free-energy surfaces in binary homogeneous nucleation theory.

J. Chem. Phys. 1999, 111, 2019-2027.

(6) Raatikainen, T. and Laaksonen, A., A simplified treatment of surfactant effects on cloud drop activation. Geosci. Model Dev 2011. 4, 107116.

(7) Topping, D., An analytical solution to calculate bulk mole fractions for any number of components in aerosol droplets after considering partitioning to a surface layer. Geosci. Model Dev. 2010, 3, 635-642.

(8) Kanakidou, M.; Seinfeld, J. H.; Pandis, S. N.; Barnes, I.; Dentener, F. J.; Facchini, M. C.; Van Dingenen, R.; Ervens, B.; Nenes, A.; Nielsen, C. J.; et al. Organic Aerosol and Global Climate Modelling: A Review. Atmos. Chem. Phys. 2005, 5 (4), 1053-1123.

(9) Clegg, S. L.; Brimblecombe, P.; Wexler, A. S. Thermodynamic Model of the System $\mathrm{H}^{+}-\mathrm{NH} 4^{+}-\mathrm{SO}_{4}{ }^{2-}-\mathrm{NO}^{3-}-\mathrm{H}_{2} \mathrm{O}$ at $\mathrm{Tropospheric} \mathrm{Tem-}$ peratures. J. Phys. Chem. A 1998, 102 (12), 2137-2154.

(10) Clegg, S. L.; Brimblecombe, P.; Wexler, A. S. Thermodynamic Model of the System $\mathrm{H}^{+}-\mathrm{NH}^{+}-\mathrm{Na}^{+}-\mathrm{SO}_{4}{ }^{2-}-\mathrm{NO}^{3-}-\mathrm{Cl}^{-}-\mathrm{H}_{2} \mathrm{O}$ at 298.15 K. J. Phys. Chem. A 1998, 102 (12), 2155-2171.

(11) Clegg, S. L.; Seinfeld, J. H. Improvement of the Zdanovskii-Stokes-Robinson Model for Mixtures Containing Solutes of Different Charge Types. J. Phys. Chem. A 2004, 108 (6), 1008-1017.

(12) Fredenslund, A.; Jones, R. L.; Prausnitz, J. M. Group-Contribution Estimation of Activity Coefficients in Nonideal Liquid Mixtures. AIChE J. 1975, $21(6), 1086-1099$.

(13) Zuend, A.; Seinfeld, J. H. Modeling the Gas-Particle Partitioning of Secondary Organic Aerosol: The Importance of Liquid-Liquid Phase Separation. Atmos. Chem. Phys. 2012, 12 (9), 3857-3882.

(14) Bilde, M.; Barsanti, K.; Booth, M.; Cappa, C. D.; Donahue, N. M.; Emanuelsson, E. U.; McFiggans, G.; Krieger, U. K.; Marcolli, C.; Topping, D.; et al. Saturation Vapor Pressures and Transition Enthalpies of Low-Volatility Organic Molecules of Atmospheric Relevance: From Dicarboxylic Acids to Complex Mixtures. Chem. Rev. 2015, 115 (10), 4115-4156.

(15) Clegg, S. L.; Seinfeld, J. H. Thermodynamic Models of Aqueous Solutions Containing Inorganic Electrolytes and Dicarboxylic Acids at 298.15 K. 1. The Acids as Nondissociating Components. J. Phys. Chem. A 2006, 110 (17), 5692-5717. 
(16) Clegg, S. L.; Seinfeld, J. H. Thermodynamic Models of Aqueous Solutions Containing Inorganic Electrolytes and Dicarboxylic Acids at 298.15 K. 2. Systems Including Dissociation Equilibria. J. Phys. Chem. A 2006, 110 (17), 5718-5734.

(17) Zuend, A.; Marcolli, C.; Peter, T.; Seinfeld, J. H. Computation of Liquid-Liquid Equilibria and Phase Stabilities: Implications for RHDependent Gas/particle Partitioning of Organic-Inorganic Aerosols. Atmos. Chem. Phys. 2010, 10 (16), 7795-7820.

(18) Zuend, A.; Marcolli, C.; Booth, A. M.; Lienhard, D. M.; Soonsin, V.; Krieger, U. K.; Topping, D. O.; McFiggans, G.; Peter, T.; Seinfeld, J. H. New and Extended Parameterization of the Thermodynamic Model AIOMFAC: Calculation of Activity Coefficients for Organic-Inorganic Mixtures Containing Carboxyl, Hydroxyl, Carbonyl, Ether, Ester, Alkenyl, Alkyl, and Aromatic Functional Groups. Atmos. Chem. Phys. 2011, 11 (17), 9155-9206.

(19) Laskin, A.; Moffet, R. C.; Gilles, M. K.; Fast, J. D.; Zaveri, R. A.; Wang, B.; Nigge, P.; Shutthanandan, J. Tropospheric Chemistry of Internally Mixed Sea Salt and Organic Particles: Surprising Reactivity of $\mathrm{NaCl}$ with Weak Organic Acids. J. Geophys. Res. 2012, 117 (D15), D15302.

(20) Yli-Juuti, T.; Zardini, A. A.; Eriksson, A. C.; Hansen, A. M. K.; Pagels, J. H.; Swietlicki, E.; Svenningsson, B.; Glasius, M.; Worsnop, D. R.; Riipinen, I.; et al. Volatility of Organic Aerosol: Evaporation of Ammonium Sulfate/succinic Acid Aqueous Solution Droplets. Environ. Sci. Technol. 2013, 47 (21), 12123-12130.

(21) Häkkinen, S. A. K.; McNeill, V. F.; Riipinen, I. Effect of Inorganic Salts on the Volatility of Organic Acids. Environ. Sci. Technol. 2014, $48,13718-13726$.

(22) Raymond, T. M.; Pandis, S. N. Formation of Cloud Droplets by Multicomponent Organic Particles. J. Geophys. Res. 2003, 108 (D15), $4469-4476$.

(23) Henning, S.; Rosenørn, T.; D’Anna, B.; Gola, A. A.; Svenningsson, B.; Bilde, M. Cloud Droplet Activation and Surface Tension of Mixtures of Slightly Soluble Organics and Inorganic Salt. Atmos. Chem. Phys. 2005, 5 (2), 575-582.

(24) Peckhaus, A.; Grass, S.; Treuel, L.; Zellner, R. Deliquescence and Efflorescence Behavior of Ternary Inorganic/Organic/Water Aerosol Particles. J. Phys. Chem. A 2012, $116(24), 6199-6210$.

(25) Ruehl, C. R.; Wilson, K. R. Surface Organic Monolayers Control the Hygroscopic Growth of Submicrometer Particles at High Relative Humidity. J. Phys. Chem. A 2014, 118 (22), 3952-3966.

(26) Padró, L. T.; Asa-Awuku, A.; Morrison, R.; Nenes, A. Inferring Thermodynamic Properties from CCN Activation Experiments: SingleComponent and Binary Aerosols. Atmos. Chem. Phys. 2007, 7 (19), 5263-5274.

(27) Walz, M.-M.; Caleman, C.; Werner, J.; Ekholm, V.; Lundberg, D.; Prisle, N. L.; Öhrwall, G.; Björneholm, O. Surface Behavior of Amphiphiles in Aqueous Solution: A Comparison between Different Pentanol Isomers. Phys. Chem. Chem. Phys. 2015, 17 (21), $14036-14044$.

(28) Ottosson, N.; Faubel, M.; Bradforth, S. E.; Jungwirth, P.; Winter, B. Photoelectron Spectroscopy of Liquid Water and Aqueous Solution: Electron Effective Attenuation Lengths and Emission-Angle Anisotropy. J. Electron Spectros. Relat. Phenomena 2010, 177 (2), 60-70.

(29) Powell, C. J.; Jablonski, A. Surface Sensitivity of X-Ray Photoelectron Spectroscopy. Nucl. Instruments Methods Phys. Res. A 2009, 601 $(1-2), 54-65$.

(30) Winter, B.; Weber, R.; Widdra, W.; Dittmar, M.; Faubel, M.; Hertel, I. V. Full Valence Band Photoemission from Liquid Water Using EUV Synchrotron Radiation. J. Phys. Chem. A 2004, 108, 2625-2632.

(31) Perrine, K. A.; Van Spyk, M. H. C.; Margarella, A. M.; Winter, B.; Faubel, M.; Bluhm, H.; Hemminger, J. C. Characterization of the Acetonitrile Aqueous Solution/Vapor Interface by Liquid-Jet X-Ray Photoelectron Spectroscopy. J. Phys. Chem. C 2014, 118 (50), $29378-29388$. 
(32) Walz, M.-M.; Werner, J.; Ekholm, V.; Prisle, N. L.; Öhrwall, G.; Björneholm, O. Alcohols at the aqueous surface: chain length and isomer effects. Phys. Chem. Chem. Phys. 2016, 18,6648-6656..

(33) Rosén, M. J.; Kunjappu, J. T. Surfactants and Interfacial Phenomena; Wiley, 2012.

(34) Prausnitz, J. M.; Sprow, F. B. Surface Tensions of Simple Liquid Mixtures. Trans. Faraday Soc. 1966, 62, $1105-1111$.

(35) Sprow, F. B.; Prausnitz, J. M. Surface Tensions of Simple Liquids. Trans. Faraday Soc. 1966, 62, 1097-1104.

(36) Li, Z.-B.; Li, Y.-G.; Lu, J.-F. Surface Tension Model for Concentrated Electrolyte Aqueous Solutions by the Pitzer Equation. Ind. Eng. Chem. Res. 1999, 38 (3), 1133-1139.

(37) Raatikainen, T.; Laaksonen, A. Application of Several Activity Coefficient Models to Water-Organic-Electrolyte Aerosols of Atmospheric Interest. Atmos. Chem. Phys. 2005, 5 (9), 2475-2495.

(38) Peng, C.; Chan, M. N.; Chan, C. K. The Hygroscopic Properties of Dicarboxylic and Multifunctional Acids: Measurements and UNIFAC Predictions. Environ. Sci. Technol. 2001, 35 (22), 4495-4501.

(39) Onorato, R. M.; Otten, D. E.; Saykally, R. J. Adsorption of Thiocyanate Ions to the Dodecanol/water Interface Characterized by UV Second Harmonic Generation. 2009, $106(36), 15176-15180$.

(40) Vanhanen, J.; Hyvärinen, A.-P.; Anttila, T.; Raatikainen, T.; Viisanen, Y.; Lihavainen, H. Ternary Solution of Sodium Chloride, Succinic Acid and Water; Surface Tension and Its Influence on Cloud Droplet Activation. Atmos. Chem. Phys. 2008, 8 (16), 4595-4604.

(41) Davies, M.; Griffiths, D. M. L. The Solubilities of Dicarboxylic Acids in Benzene and Aqueous Solutions. Trans. Faraday Soc. 1953, 49, $1405-1410$

(42) Pegram, L. M.; Record, M. T. Hofmeister Salt Effects on Surface Tension Arise from Partitioning of Anions and Cations between Bulk Water and the Air-Water Interface. J. Phys. Chem. B 2007, 111 (19), 5411-5417.

(43) Mähler, J.; Persson, I. A Study of the Hydration of the Alkali Metal Ions in Aqueous Solution. Inorg. Chem. 2012, 51 (1), $425-438$.

(44) Jalilehvand, F.; Spångberg, D.; Lindqvist-Reis, P.; Hermansson, K.; Persson, I.; Sandström, M. Hydration of the Calcium Ion. An EXAFS, Large-Angle X-Ray Scattering, and Molecular Dynamics Simulation Study. J. Am. Chem. Soc. 2001, 123 (3), 431-441.

(45) Pálinkás, G. The Structure of an Aqueous Ammonium Chloride Solution. J. Chem. Phys. 1981, 74 (6), 3522-3526.

(46) Vchirawongkwin, V.; Rode, B. M.; Persson, I. Structure and Dynamics of Sulfate Ion in Aqueous Solution--an Ab Initio QMCF MD Simulation and Large Angle X-Ray Scattering Study. J. Phys. Chem. B 2007, 111 (16), 4150-4155.

(47) Fedotova, M. V.; Kruchinin, S. E. Hydration of Acetic Acid and Acetate Ion in Water Studied by 1D-RISM Theory. J. Mol. Liq. 2011, 164 (3), 201-206.

(48) Blower, P. G.; Ota, S. T.; Valley, N. a; Wood, S. R.; Richmond, G. L. Sink or Surf: Atmospheric Implications for Succinic Acid at Aqueous Surfaces. J. Phys. Chem. A 2013, 117 (33), 7887-7903.

(49) Soule, M. C. K.; Blower, P. G.; Richmond, G. L. Effects of Atmospherically Important Solvated Ions on Organic Acid Adsorption at the Surface of Aqueous Solutions. J. Phys. Chem. B 2007, 111 (49), 13703-13713.

(50) Srinivasa Gopalan, R.; Kumaradhas, P.; Kulkarni, G. U.; Rao, C. N. R. An Experimental Charge Density Study of Aliphatic Dicarboxylic Acids. J. Mol. Struct. 2000, 521 (1-3), 97-106.

(51) Bhattacharya, S.; Saraswatula, V. G.; Saha, B. K. Thermal Expansion in Alkane Diacids - Another Property Showing Alternation in an Odd-Even Series. Cryst. Growth Des. 2013, 13 (8), 3651-3656. 
(52) Veghte, D. P.; Altaf, M. B.; Freedman, M. A. Size Dependence of the Structure of Organic Aerosol. J. Am. Chem. Soc. 2013, 135 (43), $16046-16049$.

(53) Veghte, D. P.; Bittner, D. R.; Freedman, M. A. Cryo-Transmission Electron Microscopy Imaging of the Morphology of Submicrometer Aerosol Containing Organic Acids and Ammonium Sulfate. Anal. Chem. 2014, 86 (5), 2436-2442.

(54) Laskina, O.; Morris, H. S.; Grandquist, J. R.; Qin, Z.; Stone, E. A.; Tivanski, A. V.; Grassian, V. H. Size Matters in the Water Uptake and Hygroscopic Growth of Atmospherically Relevant Multicomponent Aerosol Particles. J. Phys. Chem. A 2015, 119 (19), $4489-4497$.

(55) Cheng, Y.; Su, H.; Koop, T.; Mikhailov, E.; Pöschl, U. Size Dependence of Phase Transitions in Aerosol Nanoparticles. Nat. Commun. $\mathbf{2 0 1 5}, 6,5923-5929$.

(56) Bertram, A. K.; Martin, S. T.; Hanna, S. J.; Smith, M. L.; Bodsworth, A.; Chen, Q.; Kuwata, M.; Liu, A.; You, Y.; Zorn, S. R. Predicting the Relative Humidities of Liquid-Liquid Phase Separation, Efflorescence, and Deliquescence of Mixed Particles of Ammonium Sulfate, Organic Material, and Water Using the Organic-to-Sulfate Mass Ratio of the Particle and the Oxygen-to-Carbon Elemental Ratio of the Organic Component. Atmos. Chem. Phys. 2011, 11 (21), 10995-11006.

(57) Reid, J. P.; Dennis-Smither, B. J.; Kwamena, N.-O. A.; Miles, R. E. H.; Hanford, K. L.; Homer, C. J. The Morphology of Aerosol Particles Consisting of Hydrophobic and Hydrophilic Phases: Hydrocarbons, Alcohols and Fatty Acids as the Hydrophobic Component. Phys. Chem. Chem. Phys. 2011, 13 (34), 15559-15572.

(58) Renbaum-Wolff, L.; Grayson, J. W.; Bateman, A. P.; Kuwata, M.; Sellier, M.; Murray, B. J.; Shilling, J. E.; Martin, S. T.; Bertram, A. K. Viscosity of $\alpha$-Pinene Secondary Organic Material and Implications for Particle Growth and Reactivity. Proc. Natl. Acad. Sci. 2013, 110 (20), $8014-8019$

(59) Riipinen, I.; Yli-Juuti, T.; Pierce, J. R.; Petäjä, T.; Worsnop, D. R.; Kulmala, M.; Donahue, N. M. The Contribution of Organics to Atmospheric Nanoparticle Growth. Nat. Geosci. 2012, 5 (7), 453-458.

(60) Lienhard, D. M.; Huisman, A. J.; Krieger, U. K.; Rudich, Y.; Marcolli, C.; Luo, B. P.; Bones, D. L.; Reid, J. P.; Lambe, A. T.; Canagaratna, M. R.; et al. Viscous Organic Aerosol Particles in the Upper Troposphere: Diffusivity-Controlled Water Uptake and Ice Nucleation? Atmos. Chem. Phys. Discuss. 2015, 15 (17), 24473-24511.

(61) Bilde, M.; Svenningsson, B. CCN Activation of Slightly Soluble Organics: The Importance of Small Amounts of Inorganic Salt and Particle Phase. Tellus B 2004, 56 (2), 128-134.

(62) Rastak, N.; Silvergren, S.; Zieger, P.; Wideqvist, U.; Ström, J.; Svenningsson, B.; Maturilli, M.; Tesche, M.; Ekman, A. M. L.; Tunved, P.; et al. Seasonal Variation of Aerosol Water Uptake and Its Impact on the Direct Radiative Effect at Ny-Ålesund, Svalbard. Atmos. Chem. Phys. 2014, 14 (14), 7445-7460.

(63) Tesche, M.; Zieger, P.; Rastak, N.; Charlson, R. J.; Glantz, P.; Tunved, P.; Hansson, H.-C. Reconciling Aerosol Light Extinction Measurements from Spaceborne Lidar Observations and in Situ Measurements in the Arctic. Atmos. Chem. Phys. 2014, 14 (15), $7869-7882$.

(64) Booth, A. M.; Topping, D. O.; Mcfiggans, G.; Percival, C. J. Surface Tension of Mixed Inorganic and Dicarboxylic Acid Aqueous Solutions at 298.15 K and Their Importance for Cloud Activation Predictions. Phys. Chem. Chem. Phys. 2009, 11 (36), 8021-8028.

(65) Farmer, D. K.; Cappa, C. D.; Kreidenweis, S. M. Atmospheric Processes and Their Controlling Influence on Cloud Condensation Nuclei Activity. Chem. Rev. 2015, 115 (10), 4199-4217.

(66) Sahu, K.; McNeill, V. F.; Eisenthal, K. B. Effect of Salt on the Adsorption Affinity of an Aromatic Carbonyl Molecule to the Air-Aqueous Interface: Insight for Aqueous Environmental Interfaces. J. Phys. Chem. C 2010, 114 (42), 18258-18262. 
TOC

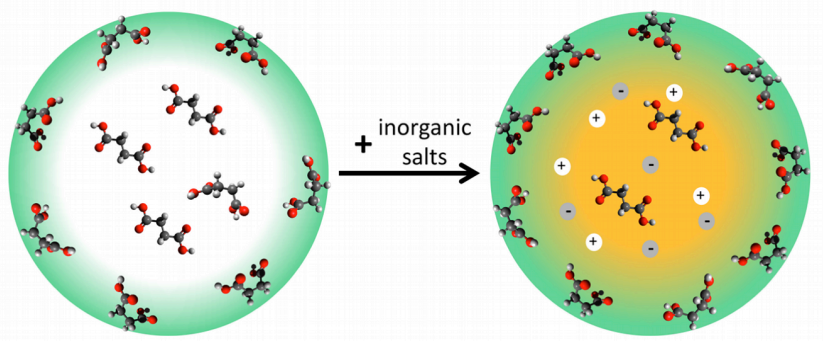

